\title{
Public health nutrition and genetics: implications for nutrition policy and promotion
}

\author{
Ian Darnton-Hill ${ }^{1 *}$, Barrie Margetts ${ }^{2}$ and Richard Deckelbaum ${ }^{1}$ \\ ${ }^{1}$ Institute of Human Nutrition, Columbia University, PH15 East-Room 1512, 630 West 168th Street, \\ New York, NY10032, USA \\ ${ }^{2}$ Institute of Human Nutrition, University of Southampton, Southampton General Hospital, \\ Southampton SO16 6YD, UK
}

\begin{abstract}
The unravelling of the human genome has the potential to radically extend many of the strategies used in public health nutrition to improve health and to increase food availability, accessibility and utilization. The present paper divides nutrigenomics into two broad but differing areas in asking about possible public health applications: (1) the increasing mismatch between population growth and global food security, on top of the already approximately 800 million of the world population who are food insecure; (2) possible responses to the rising prevalence of non-communicable diseases as the Western diet becomes increasingly inappropriate to the needs of those consuming it. It is clear that complex interactions of multiple polymorphisms play a role in how individuals and sub-populations respond to dietary interventions. All these applications present public health and ethical challenges, particularly in ensuring that any benefits that do come from nutrigenomics are not restricted to the wealthy minority of only the affluent nations. The present paper concludes that the public health applications of nutrigenomics are probably at least a decade away, especially for developing countries. Clinical applications are likely to be more immediate, probably resulting in 'designer diets' for individuals with particular polymorphisms, but unless governments take on the role of ensuring some extent of equity in access, any benefits are most likely to go to those who can afford the screening, tests and treatment. At the same time, greatly increased international efforts are needed towards the continuing, and in some cases worsening, global malnutrition, as genetic manipulation of crops is unlikely to provide more than part of the solution.
\end{abstract}

GM organisms: Micronutrients: Non-communicable diseases: Nutrigenomics: Public health nutrition

Public health nutrition aims to develop 'population-based strategies to promote good health through healthy diets' (Mensink \& Plat, 2002). This guiding principle has been recognized for at least 50 years, since Keys et al. (1965) recognized that '... responsiveness to change in the diet tends to be related to the intrinsic characteristics of the individual', and has been accepted community wisdom for very much longer. Broadly speaking, public health nutrition, among other objectives, seeks to reduce global and household food insecurity, improve the quality of diets and prevent and control nutritionally-related diseases. This framework will be used here.

It has been acknowledged since the start of nutrition science that individual variability is present and affects the individual's dietary and nutrient requirements, as well as their nutritional status and hence health. For this reason the RDA is the median and $2 \mathrm{SD}$ (where these values are known) and upper and lower ranges are often given, e.g. upper tolerable levels of intakes, and these levels can vary according to age, gender and ethnicity (Walter et al. 2001; Karter, 2002). The unravelling of the human genome and much of the work on the genetics of man, and the human food supply and diseases may assist in addressing individual variability, or may just make it even more complex, e.g. as the extent of this variability is increasingly understood through the identification of increasing numbers of genetic polymorphisms (Krauss, 2000; Stover \& Garza, 2002a). New paradigms for addressing chronic diseases as being caused by gene instability are already being proposed, especially with the increasing longevity of most 
populations (Fenech, 2003). These paradigms would have nutritional consequences in terms of recommended increased intakes of some micronutrients and other dietary recommendations, and will affect how individuals access health care, especially in terms of nutritionally-related diseases that have a clear genetic component in their aetiology (Simopoulos, 2002; Kavalier \& Kent, 2003).

From a utilitarian point of view, the ethical basis on which much of public health is implicitly based, effective public health nutrition interventions generally rely on the notion of the greatest good for the greatest number of the population (Beauchamp \& Childress, 1994). Some interventions appear to be safe across a whole range of populations and there is little argument against their use, although cost-effectiveness must be sufficiently positive, or to be seen as such, in order to continue to convince health policymakers that the investment and the rewards are appropriate. One of the burdens that public health nutrition interventions have to bear is that they are never completed. For example, even if elimination of the iodine-deficiency disorders is declared and documented, it relies on susceptible populations living in the same endemically iodine-deficient environments continuing to receive iodine indefinitely (most often through fortified salt), or at least until a better system of ensuring adequate iodine nutrition is found (Andersson et al. 2004). Genetic manipulation could conceivably, at some future date, help to improve the sustainability of some public health nutrition interventions (Stover \& Garza, 2002b) by addressing the physiological needs of individuals in susceptible populations, or by changing the disease environment.

The present paper looks at the public health ramifications of the nutrition and gene interface of nutrigenomics. At present, there are two dominant areas of investigation in nutrigenomics, relating to impact on: (1) global and household food insecurity; (2) improved prevention and management of nutritionally-related non-communicable diseases.

In discussing the first area of investigation, food security and genetic manipulation of crops and foods to improve the diets of populations, two broad strands will be used as examples: (1) reducing global and household food insecurity by using biotechnology, particularly looking at increasing the yields of cereal crops and other staples by genetic manipulation of foods (GM foods or organisms); (2) improving the quality of diets, especially of populations living in poverty, by increasing the content and bioavailability of micronutrients. The latter particularly concerns the micronutrients of most public health interest, such as Fe, Zn, folate and vitamin A, and can be achieved by improving accessibility and availability through plant breeding, fortification and supplementation. The implications of both broad approaches will be examined.

In relation to the second area of investigation the present paper will discuss: (a) the global epidemic of chronic (or non-communicable) diseases, looking particularly at susceptibility to changing diets and exercise patterns that are leading to over half some adult national populations being overweight and obese; (b) population variation in response to diet and what this variation might mean for population-level public health recommendations.
The implications of both factors for public health nutrition practice will be addressed. Little attention will be paid to the manipulation and development of novel or functional foods, although progress in this area may eventually have important public health implications for the prevention and management of some chronic diseases (Simopoulos, 2002; Wahlqvist, 2002).

The ultimate question being addressed in the paper is whether biotechnology and nutrigenomics will make an important difference to the health of the public.

\section{Reducing global and household food insecurity}

There are many dimensions to improving household food security beyond the simple provision of, and access to, sufficient food at a community or societal level. In the present paper, because of space constraints, attention is focused on those issues that relate primarily to increasing either the quantity or quality of the food supply. This focus does not imply that food supply per se is the main constraint on households being able to achieve food security, but this issue is bigger and beyond the scope of the present paper. There is also a brief discussion of the manipulation of plants to produce vaccines and other possible therapeutic uses.

\section{Improving crop yields (increasing quantity)}

The 1960s were considered to be 'a decade of despair' in relation to the world's ability to cope with the food population balance (Khush, 2001). Among dire, and not unreasonable, predictions included: 'in 15 years, the famines will be catastrophic and revolution and social turmoil and economic upheavals will sweep areas of Asia, Africa and Latin America' (Paddock \& Paddock, 1967). However, there was widespread adoption of 'Green Revolution' technology, so that whereas, between 1960 and 1990, the population of low-income countries grew by $80 \%$, food production doubled (Khush, 2001). It also meant that in 1997, the average per capita food availability was $18 \%$ greater than that in 1966.

The widespread adoption of the 'Green Revolution' was facilitated by: (a) the development of new grain varieties by plant breeding; (b) the development of irrigation facilities; (c) the availability of inorganic fertilizers; (d) generally facilitative government policies. The new rice varieties produced 5-7t unmilled rice/hectare $v$. 1-3 $\mathrm{t} /$ hectare for conventional varieties, and a six-fold increase in wheat production in Asia (Khush, 2001). The proportion of the population of the developing world that was malnourished fell from $46.5 \%$ to $31 \%$ between 1965 and 1995 (ACC/SCN, 2000). The increase in the per capita availability and decreased cost of production led to a decrease in the real price of rice and wheat.

In the 1990s there was continued population growth, a drastic slowdown in the expansion of cereal production, a reduction in other crops (e.g. legumes and coarse grains) and changing food habits, such as increased consumption of animal foods and fruits and vegetables. At the same time there was increasing recognition of environmental damage and constraints, such as the marginalization of 
less-productive lands, water and salination, and damage from excessive fertilization. In the Indian sub-continent over half the children $<5$ years of age continue to be malnourished, while in sub-Saharan Africa the situation is actually deteriorating (ACC/SCN, 2000).

Clearly, there was a need for the next 'Green Revolution'; perhaps the new tools of genetically modifying foods were to be the answer. At the same time, there was continued research and development on the genetic improvement of crop cultivars to increase yields (by modification of plant types, hybridization e.g. with wild strains and increasing attention to genetic stability and tolerance to environmental stress) by conventional, and effective, methods (Welch \& Graham, 2000; Bouis, 2002b). This improvement programme has continued, despite ever decreasing public expenditure on research and development (Pinstrup-Andersen, 2000). It was also recognized that there was a need to revise management strategies that addressed such areas as production inputs (water and nutrients) and their real costs, including environmental costs of non-renewable resources. A further avenue was to decrease losses by, for example, integrated pest management and reducing post-harvest losses, and there was a need for responsible government policies and an understanding of a controlled role for the private sector.

However, there were other consequences and realizations, probably the main one being that there are limits to expanding food supplies, at least using such tools, dramatic though the results had been. Further advances are possible, such as in 'biofortification', double cropping, inter-cropping and biotechnology (Bouis et al. 2002; Khush, 2002). However, there are still ecological and environmental constraints in terms of fertilizer use, farming of marginal lands and social issues of whether the very poor receive their share of the improved yields. There were also nutritional consequences as the new grain crops displaced legumes and other contributors to dietary adequacy in poor diets (Haddad, 2000).

Consequently, much hope is being held in the promise of genetic manipulation of plants and animals to make the next great leap forward. Further increases in crop output globally will come from increased land under cultivation (especially land previously unsuitable because of trace element deficiencies, high salinity or being too dry), increasing crop yields through genetic modification (either by plant breeding or by introducing genetic material from another organism that will increase yields) and by decreasing post-harvest losses. These factors would all increase availability, although this increase would be taking place against a background of increasing amounts of grain being used for animal feed. Increasing accessibility, especially to poorer populations, would also have to take place, even if crop yields do markedly increase.

However, there are almost certainly limits and raising world cropland productivity is becoming more difficult (Brown, 2001). As Brown (2001) has pointed out, the heart of the effort, as plant breeders dramatically boosted the genetic yield potential of wheat, rice and maize, was an increase in the share of the plant's photosynthate, the product of photosynthesis, going to the seed. The theoretical upper limit is estimated at $60 \%$ (v. $20 \%$ for originally domesticated wheat, which rose to $\geq 50 \%$ in improved varieties) since the plant's roots, stem and leaves also require photosynthate (Brown, 2001). This estimate suggests a potential limit for higher-yielding grains and perhaps other staples, although they have been less exploited for their potential than the three main grain staples.

A further issue, besides macronutrient increases, is the profitability of new crops, which will not be taken up by small subsistence farmers (or large farmers for that matter) if the nutritionally-enhanced crop is not as viable or profitable as the crop it is replacing. Thus, genetic modification is not only used to increase the nutritional quality of plants and food (in fact, it is far less commonly used for this purpose), but more commonly it is used to achieve a desirable commercial quality, e.g. 'switching off' the gene that is responsible for fruit softening, or 'switching on' the gene that makes a plant resistant to a pest (Food Standards Agency, 2003). It is worthwhile remembering in this debate on GM foods that foods widely available in the UK at present, such as 'calrose 76' rice, 'alamo- $\mathrm{X}$ ' oats and 'golden promise' barley, were all produced for different qualities, such as shorter stalks, resistance to blight and higher yields with good malting qualities respectively, by irradiation using $\gamma$ or $\mathrm{x}$ rays (Food Standards Agency, 2003).

The important issue, however, is just how much will genetic modification actually help to close the hunger gap. Genetic manipulation (through conventional breeding methods) helped the developing world in the 1970s, but even with GM foods it is argued that there is a limited extent to which yields can continue to be greatly expanded (Brown, 2001). For example, the genetically-enhanced potato developed in India by implanting a gene from the amaranth plant (a traditional, widely-eaten food) has a $40 \%$ higher protein content, which actually translates into $28 \mathrm{~g}$ protein $/ \mathrm{kg}$, an incremental increase on usual potatoes that is unlikely to lead to any marked impact on health (Murdur, 2003). However, it has been pointed out that potatoes are eaten by the very poor and therefore any increase is welcome.

It is apparently more likely that the advances will be in increasing the negative terrains in which crops can be grown, such as dry, high-saline and generally more marginal lands, but even this strategy will have environmental and ecological consequences, and already limits are apparent. Between 1950 and 1981 the area in grain expanded from $587 \times 10^{6}$ hectares to its historical peak of $732 \times 10^{6}$ hectares and by 2000 had fallen to $656 \times 10^{6}$ hectares, as a result of a combination of poor farming practices on marginal lands, encroachment by urban areas and economic failures (Larsen, 2003). Half the world's annual population growth of seventy-seven million occurs in just six countries, Bangladesh, China, India, Indonesia, Nigeria and Pakistan. Each of these nations faces a steady shrinkage of grain land per capita and will, therefore, be heavily dependent on future grain imports. In countries that already have heavy levels of undernutrition, it is unclear whether they will be able to import all that is needed, or that global grain markets will actually be able to meet their added demands (Larsen, 2003). 
Projects in their early stages include: the development of a tomato plant variety that will grow in soil containing high levels of salt; the removal of a trigger protein for an allergy from rice; the protection of plants from mould (Food Standards Agency, 2003); all of which are worthwhile, but none of them is likely to make a substantial impact on relieving the world's hunger. Virtually none of the current global commercial GM crop developments are being directed towards alleviating hunger in the poorer parts of the world. Increased yields of soyabean $(51 \%$ GM), maize (9\% GM), cotton (20\% GM) and oilseed rape (11\% GM; data from Food Standards Agency, 2003) are not likely to contribute much, as most of the maize will go to animal feed, the soyabean crops to processed foods and the cotton is, if anything, likely to have a negative impact on the economics of the Third World, e.g. in West Africa (Toumani Touré \& Compaoré, 2003). However, maize, soyabean and oilseed are the major sources of energy and protein for UK livestock (Food Standards Agency, 2003), as they are for many other industrialized countries, especially the USA.

The implications are, in essence, that while biotechnology is often cited as a potential source of higher yields, biotechnologists have been engineering new plant varieties for two decades and they have yet to produce a single variety of the three major grains (wheat, rice and maize) that could dramatically increase yields (Brown, 2001). It is suggested this lack of success is because the conventional plant breeders have already made most of the possible improvements in terms of plant structure to raise yields. However, where pest resistance has been an important part of the genetic modification, along with other factors such as protection from a specific herbicide, then economies of scale prevail. In the USA, where $30 \%$ of the maize is GM, and other countries, e.g. Argentina where $90 \%$ of the soyabean crop is GM, increased yields, and therefore increased profits, are being made. It is suggested, therefore, that most of the contribution of biotechnology is likely to come from developing crop varieties that reduce insecticide use, are more drought tolerant or more salt tolerant (Brown, 2001). The potential for plant breeding is that it could, if successful, reach out to the most remote farming communities and could also increase productivity, particularly in trace mineral-deficient soils in arid areas, and that it is cost-effective and sustainable (Bouis, 2002a). However, given the priorities mentioned earlier and seed macronutrient potential, current biotechnological approaches to genetic manipulation seem unlikely to play a major role in reducing global food insecurity. A possible exception might be if a drought-resistant food crop becomes well established over large parts of Africa.

\section{Improving quality of diets}

If there appears to be a more limited role for biotechnology in expanding yields than has been hoped, improving the quality of diets may hold more promise (Bouis et al. 2002; Khush, 2002). The micronutrient content of diets, in particular, could be improved, as deficiencies in quality, even more so than quantity, are more likely to occur in the diets of those living in poverty. There are four recognized broad approaches to reducing micronutrient malnutrition, a problem affecting at least two billion of the world's population: (1) increasing dietary diversity through improved micronutrient availability, knowledge and accessibility; (2) improving access through fortification; (3) increasing intakes through supplementation; (4) supportive public health measures (such as the promotion of breastfeeding), social policies (such as poverty alleviation) and social factors (such as reducing the disease burden; Darnton-Hill, 1998). The present paper focuses primarily on reviewing attempts to increase dietary diversity.

Increasing dietary diversity. In order to increase dietary diversity, micronutrient availability, accessibility and utilization and the reduction of losses all need to be improved. Some interventions will address more than one of these factors. Here the focus is on research that has attempted to increase the micronutrient content of staple foods by genetic enhancement. In order to improve household food security in the poorest families, it is necessary to consider the main food sources for this sector and the potential for improvement in these staple crops. The four main methods of achieving this improvement are to: (1) increase minerals and vitamins in the staple food by conventional plant breeding; (2) increase minerals and vitamins by the introduction of genes that code for trace element-binding proteins, by over-expression of storage proteins already present or increased expression of proteins that are responsible for trace element and micronutrient uptake into the plants; (3) decrease the levels of inhibitors or anti-nutrients that inhibit bioavailability, such as phytates; (4) increase enhancing compounds that increase bioavailability such as ascorbic acid or citric acid (Lonnerdal, 2003).

The potential for 'biofortification' is apparent from the example of existing germplasm varieties that have been identified as having $\mathrm{Fe}$ concentrations ranging from 6 to $24 \mathrm{mg} / \mathrm{kg}$ and $\mathrm{Zn}$ concentrations of $15-58 \mathrm{mg} / \mathrm{kg}$ (Bouis, $2002 b$ ). Physical attributes that can be useful are modifications to tall, traditional and low-yielding varieties (to improve yields), reducing the effect of milling (to reduce losses of Fe, thiamin and other B-vitamins), and emphasizing the grain as opposed to other parts of the plant (which of course must still be able to support the grain) in order to increase the levels of micronutrients in the grain. Increased micronutrient content has been described in cereals, legumes and tubers; for example, rice and legumes selected for increased $\mathrm{Fe}$, carrots and sweet potatoes for $\beta$-carotene and maize with reduced phytate and increased Fe and $\mathrm{Zn}$ absorption (Bouis, 2002b). For vitamin A, four new enzymes were introduced from the daffodil (Narcissus pseudonarcissus) and Erwinia uredovora to produce $\beta$-carotene in the rice grain where it did not exist before to produce 'golden rice'. Wheat, cassava, sweet potato and maize have all been successfully genetically manipulated to increase $\beta$-carotene, as have rice and maize to contain high ferritin content, although the efficacy and effectiveness of these approaches still needs to be demonstrated (Lonnerdal, 2003). The potential for improving carotene, $\mathrm{Fe}$ and $\mathrm{Zn}$ content in maize and cassava genotypes through plant breeding has been established (Maziya-Dixon et al. 2000). 
The increased micronutrient content may also improve accessibility to the poor by reducing costs, as many of these higher-micronutrient grains have also shown improved yields (Bouis, 2002a), and by decreasing inputs, e.g. herbicides and amount of fertilizers. Biofortification has been explicitly cited as improving accessibility, e.g. to poor and remote farming areas where fortified processed foods may not reach (Bouis, 2002a). However, even most of the groups involved in promoting these approaches consider that no single intervention will solve the problem of micronutrient malnutrition (Bouis, 2002b; Lonnerdal, 2003). The reason is partly that biofortification of staple foods cannot deliver as high a level of minerals and vitamins as supplementation or industrially-fortified foods. Other reasons include the observation that enzymes genetically introduced to reduce phytate, e.g. microbial phytases (e.g. from Aspergillus fumigatus) introduced into wheat and rice, were inactivated by boiling and cooking temperatures (Lonnerdal, 2003). Even increasing the levels of expression of trace element-binding proteins, so that more atoms of trace element are bound per protein molecule, has not necessarily been the solution. For example, the introduction of human lactoferrin into rice to bind $\mathrm{Fe}$ increased the Fe content by $\geq 120 \%$, but it is still unlikely to provide substantial dietary Fe; a similar outcome was found when ferritin from Phaseolus vulgaris was introduced into rice (Lonnerdal, 2003). Sometimes the micronutrient-binding protein is not where it would be most useful, e.g. leghaemoglobin is present in the root nodules of legumes, but when introduced from soyabeans into potatoes there was reduced growth of the potato tuber and reduced production (Lonnerdal, 2003). Various dietary ligands can enhance micronutrient absorption, e.g. cysteine or cysteine-rich peptides increase Fe absorption and histidine facilitates $\mathrm{Zn}$ absorption. Inserting a gene for a rice metallothionine-like protein that contains a large number of cysteine residues has potential, but the long-term effects are not known. Furthermore, Lonnerdal (2003) cautions about the possibility that high-level expression of metal-binding proteins may lead to accumulation of toxic metal ions.

Nevertheless, for poor populations food staple consumption so dominates diets that primary food staples can provide $40-55 \%$ of the total Fe intake in lower-income households. While doubling the existing low levels of a particular micronutrient would certainly help, it has been calculated that in Bangladesh it would reduce rates of anaemia among the women in lower-income households by only 3-6\% (Bouis, 2002b). Although this improvement is modest, the simulation estimated that it would mean that forty-four million cases of anaemia per year could be prevented in Bangladesh and India if $10 \%$ of total rice crop were to comprise the newly-biofortified varieties (Bhargava et al. 2001). This outcome represents a benefit:cost of $19: 1$, and if expected benefits of higher agricultural productivity are factored in it would be $79: 1$. Calculations for the adoption of 'golden rice' are that it might increase total provitamin A by 23-26\% of the requirements for adult women and preschool children (or $\leq 80 \%$ if bioconverted at more efficient rates, as might be the case because of the physical characteristics of the rice endosperm; Bouis, $2002 b)$.
The implications are that 'significant advances will be made in the near future with regard to establishing GM foods with increased contents of trace elements and optimized composition of enhancers and inhibitors of trace elements' (Lonnerdal, 2003). However, the author goes on to caution that much further research is needed to prove that this approach will lead to healthy plants and that the micronutrient status will be markedly improved in consuming populations, as well as needing to resolve the social issues of property rights, economic implications (such as not being able to export to the EU market) and acceptability and safety issues. The time frame is not expected to be anything less than another decade for both conventional plant breeding and GM staples.

GM plants and animals to produce vaccines and medicines. While much of the controversy has been about plants as food and the genetic manipulation of them, there is also the extraordinary area of manipulating plants to produce vaccines and other possible medicines. In the area of pharmaceutical production there are already preliminary results on vaccines from fruit and vegetables, maize that will benefit cystic fibrosis sufferers etc. At Thomas Jefferson University genetically-engineered tobacco mosaic virus has been inserted into spinach (Spinacia oleracea) plants, instructing the plant to manufacture fragments of protective antigen of Bacillus anthracis, which is needed to develop anthrax vaccine (Crop Biotech Net, 2003b). Whether this development is seen as an amazing opportunity or a sin against nature is a matter of individual perspective, but a perspective that seems to be becoming more polarized.

Currently, infectious diseases seem a less fertile area, except in the development of novel ways of delivering vaccines through GM foods. The contribution of undernutrition to infectious disease mortality has again been demonstrated in a recent article by Black et al. (2003), showing it to be a major cause of mortality, with foodborne diseases remaining the major cause of diarrhoeal morbidity and mortality throughout the world, especially as the pathogens continue to evolve. The genomic sequences of approximately ninety bacterial genomes, including several food-borne pathogens, have been identified and should give useful insights into possible prevention and treatment options (Wells \& Bennik, 2003). Such techniques have also highlighted the extent of genetic diversity among many food-borne bacterial pathogens (Wells \& Bennik, 2003). Genes from rice have been inserted in an East African cooking banana, matooke, to give it resistance to nematodes, with potential implications for human health.

\section{Implications}

It is clear that the quality of diets or increased intakes of micronutrients can be achieved through a variety of public health and therapeutic measures. There has already been considerable success both in reducing undernutrition (although not in sub-Saharan Africa) and in reducing micronutrient malnutrition (although not Fe-deficiency anaemia). The role of nutrigenomics in maintaining and improving on this success is likely to be modest but 
helpful. 'Biofortification' has promise, especially to reach outlying farming communities, or if a staple with markedly more $\mathrm{Fe}$ and $\mathrm{Zn}$, increased enhancers or decreased phytates or other inhibitors becomes the new staple variety for a particular population. GM grains and other staples such as roots and tubers show promise, but progress has been slow to this point, in terms of possibilities for scaling up. Targetted manipulation of the food supply by the introduction of GM traditional and novel foods has been claimed to have the potential to replace nutritional supplements and/or fortification approaches (Stover \& Garza, 2002a).

In terms of safety and ethical issues, (AA Jackson, personal communication) has noted that 'the standard studies which might be expected to be carried out to demonstrate the nutritional safety of these (GM organisms) products for animal and human consumption have not been carried out' and furthermore 'do not provide sufficient evidence that these products are safe for consumption in the nutritionally vulnerable over extended periods of time'. Others, including the US and some other governments, would not agree, citing over a decade of US populations eating GM-derived products. Nevertheless, reservations remain strong in consumer groups, environmental groups and many scientists about GM foods (Rowland, 2002) but with a very marked trans-Atlantic divide, reflecting different views of risk and the role of government (Darnton-Hill et al. 2002; Finucane, 2002). This divide is reflected in the opinion that would appear to be that of a majority of Europeans. The UK government recently undertook a 6-week nationwide public debate on GM food that effectively maintained the status quo (against expanding the role of GM foods in the British diet).

From a developing country perspective, much of the discussion seems to be one of wishing not to be bullied into decisions, one way or the other. It has also been noted that much of the discussion has been undertaken outside the developing countries (Finucane, 2002). A report from the Nuffield Council on Bioethics is reported as saying that GM crops could help small-scale farmers in developing countries: 'GM crops will not eliminate the need for economic, political or social change, or that they will feed the world. However ... (such) technology could make a useful contribution, in appropriate circumstances, to improving agriculture and the livelihood of poor farmers in developing countries' (see Crop Biotech Net, 2003a). An important recent controversy followed when the UN World Food Programme was given food relief supplies from the USA, which contained GM grain. Many African countries of South and East Africa felt they were being forced to take it because of the ongoing famine, despite existing legislation or ongoing in-country discussions on the acceptability of GM foods, and potential retribution by importing countries in Europe. As it happened, much of grain was milled in-country, which then meant it could be fortified. On the other side, the African Biotechnology Stakeholders Forum has recently stated, in response to draft legislation on zero tolerance levels for the unintended presence of GM material in non-GM agricultural and food products, that as much as they 'acknowledge the EU concern ... African farmers should be given a chance of choice on the technologies available' (Crop Biotech Net, 2003c). AA Jackson (personal communication) also noted that apparently no studies have been carried out on the safety of GM foods in animals of poor nutritional status, and it would be unethical to undertake such studies in human populations (although a major population experiment has been taking place for some years in US populations, without apparent harm).

\section{Improved prevention and management of nutritionally-related disease}

This section briefly examines the role of genetics in obesity and the non-communicable diseases, especially in light of the emerging global epidemic. It then goes on to look at the implications for prevention and management of disease, including the options of dietary management by modifying diets and/or recommendations for populations and for individuals, and fortification, and very briefly supplementation, as they apply to diseases not conventionally thought of as deficiency diseases. The present paper then concludes with a discussion of the implications of these approaches, including some ethical issues, and ends with tentative conclusions for nutrigenomics and public health.

\section{Genetic susceptibility, or resistance, to disease}

The roles of the phenotype and the environment are widely accepted, along with physical activity, as important in the development of chronic disease. The role of the genotype is better described in laboratory animals and better applied in farm animals, but is clearly also a major influence in human non-communicable diseases, including obesity. Most of the earlier attention was given to rare Mendelian single-gene diseases and the growth of the discipline of genetic counselling (Haan, 2003). However, the diseases emerging globally are the results of complex interactions of an individual's genetic makeup, their environment throughout life, including before birth, and lifestyle in the broadest sense (World Health Organization, 2002d; Darnton-Hill et al. 2004). Social disadvantage, stress and inter-generational effects all play unquantified and varying roles. The more complex diseases of nutritionally-related chronic aetiology are likely to be very much less susceptible to current methods of genetic counselling and intervention, and thus raises the question of the role of public health interventions. This situation is complicated further, and aggravated, by the fact that polymorphisms may have several phenotypic effects associated with disease (Davey Smith et al. 2003).

The burden of chronic non-communicable diseases is rapidly becoming larger worldwide and is also increasingly affecting the developing world. By 2020, the global burden of chronic diseases is expected to increase to $57 \%$ of all disease, at enormous healthcare and other costs for societies and governments (World Health Organization, $2002 c$ ). Already $79 \%$ of deaths attributable to non-communicable diseases are occurring in developing countries, predominantly in middle-aged men (World Health Organization, 2002c). 
There has been an ongoing scientific discourse on the contribution of the genotype to obesity, and the consensus appears to be that susceptibility to obesity clearly has a large genetic component and that some genotypes are at greater risk when living in, or moving to, an obesogenic environment (Allison et al. 2001). Obesity, in fact, is one area in which the application of both genomic and nutritional genomic approaches has already been highly successful. It led to the identification, by positional cloning, of the gene that in mutated form results in the obesity of the ob/ob mouse (Zhang et al. 1994), which in turn led to the discovery of the previously unknown protein, leptin, and its receptors. Leptin provides a direct signal from the adipose tissue to the brain and also led to the identification of white adipose tissue as an endocrine organ and not just the site of lipid storage. Mutations in the leptin and receptor genes have subsequently been shown to be associated with obesity in man, as have polymorphisms in several unrelated genes (Trayhurn, 2003).

The current epidemic of obesity is a result of a combination of factors (World Health Organization, 2002b, 2003), including a decrease in physical activity, as well as an increasingly obesogenic environment with widespread advertising, increased and round-the-clock availability of high-energy high-fat foods, which are themselves of increased serving sizes, and the ubiquity of soft drinks. These trends are particularly seen in the USA, but similar trends are showing up in most countries (Popkin, 2002). The control of body weight and composition depends on food intake, nutrient turnover and thermogenesis and body fat stores, which all have complex feedback mechanisms and are affected by susceptibility genes that in turn may influence energy expenditure, fuel metabolism, muscle fibre function and appetite or food preferences. Thus, the picture is increasingly complex and something of a moving target (Martinez, 2000). However, as the increasing rates of obesity cannot be explained by shifting gene pools, it seems likely that genetic variants that were previously 'silent' are now being triggered by the high availability of energy and fat-dense foods and by the increasingly sedentary lifestyle of modern societies (Martinez, 2000). Indian sub-continent populations, for instance, have an apparent higher likelihood of CVD and diabetes at the same BMI (Whincup et al. 2002; Yajnik, 2002), and it may be that lower BMI (but with greater percentage fat) in several Asian populations may represent an increased risk (World Health Organization, 2004), but not in all Asian populations (Stevens \& Nowicki, 2003).

There are two over-arching concerns. Given the observed ethnic and geographical variation in chronic disease prevalence, and risk factors such as serum lipoproteins, as evidenced by differing frequencies of polymorphisms (Saha et al. 1995), can populations of increased susceptibility to the epidemic of chronic diseases be identified? If so, can this knowledge help in preventing the epidemic coming to these countries or, perhaps, knowing the genetic susceptibility, help prepare for a major epidemic of chronic diseases such as diabetes? One way of looking at this problem might be to look at population variation in response to diet.

\section{Population variation in response to diet}

Implicit in this discussion is the possible use of response to dietary manipulations to obtain a particular effect, such as reducing a risk factor, e.g. the role of nutrients in gene expression such as PUFA suppressing fatty acid synthase (mRNA) expression (Simopoulos, 2002). Wide interindividual variation in the lipid and lipoprotein responses to dietary change has been observed and the existence of consistent hypo- and hyper-responders supports the hypothesis that responsiveness is related to genetic variation (Ordovas, 2004). The heterogeneity in responsiveness to changes in dietary fat, cholesterol and fibre is explained by variations in genes, the products of which affect lipoprotein metabolism, e.g. apo, enzymes and receptors (Masson et al. 2003). However, these effects are all likely to be polygenic and will depend on the current BMI or amount of fat and type of fats already existent, and even lifestyle. For example, the effect of the variant allele $\varepsilon 4$ of apoE on CHD risk does not appear unless the individual is also a smoker (Talmud, 2004). In other examples, whether some of the expected effects will be seen will depend on the polymorphism. For example, subjects carrying the A allele of a common genetic polymorphism that influences the effect of dietary PUFA intake in HDL-cholesterol concentrations show an increase in HDL-cholesterol concentration with increased intakes of PUFA, whereas those who are homozygotes for the more common $\mathrm{G}$ allele have the expected lowering of HDL-cholesterol levels as the intake of PUFA increases (Ordovas, 2004).

Given the multiplicity of genes involved in key metabolic pathways, it is likely that differences in groups of genes, rather than in individual genes, are required to generate major inter-individual differences in responsiveness to diet (Krauss, 2000). Genetic influences on LDLcholesterol concentrations represent a composite of effects on lipoprotein production, intravascular metabolism and plasma clearance and composition, each of which may have multiple genetic influences. Variations in the genes for apoA-1, apoA-IV, apoB and apoE all demonstrate evidence of the heterogeneity in the lipid response to dietary interventions (Masson et al. 2003).

While human diets have markedly evolved since their origin, the human genome has only marginally changed. Nevertheless, polymorphisms of common genes are widespread, including those genes key to major disease risk factors such as apo, LDL receptor, microsomal transfer protein, fatty acid-binding protein, cholesteryl ester transfer protein etc., and have been linked to variable responses to diets (Vincent et al. 2002). As already noted, unlike the rare and severe genetic defects that cause monogenic diseases, the genetic factors that modulate the individual susceptibility to multifactorial diseases (such as CVD, cancers, diabetes, etc.) are common, functionally different, forms of gene polymorphisms, which generally have a modest effect at an individual level but, because of their high frequency in the population, can be associated with a high attributable risk (Tiret, 2002). It is also suggested that most of the susceptibility genes for common diseases do not have a primary aetiological role in predisposition to disease, but rather act as response modifiers to exogenous 
factors such as stress, environment, disease and drug intake (Tiret, 2002).

There are also the established ethnic and geographical differences, e.g. throughout the various ethnic groups in Singapore (Heng et al. 1997) and elsewhere (K Cruickshank, unpublished results), but there is a strong likelihood that many of these predispositions only become apparent when members of that particular ethnic population, or subsets of it, become overweight, i.e. the effects are not initiated until a certain BMI is reached. Thus, any recommendations will be a moving target depending on changing dietary composition, ethnicities, gender and changing body masses as societies become heavier and eat more 'Westernized' diets.

However, Simopoulos (2002) has suggested that this very variation and heterogeneity argues against general recommendations. For example, increasing the PUFA content of the diet to decrease plasma cholesterol level and the risk for coronary artery disease is not appropriate for women with the apoE3/2 phenotype, as such women stand to benefit least from a high PUFA:saturated fatty acid diet because of a reduction in the more 'protective' HDL-cholesterol, whereas men of the apoE4/3 phenotype show the greatest improvement in LDL-cholesterol: HDL-cholesterol (Simopoulos, 2002). Similarly, oat bran has been shown to decrease serum cholesterol in some studies and not others, and possibly only subjects with the apoE3/3 phenotype have a response but not the apoE4/4 or apoE4/3 phenotypes. Furthermore, the variant apoA-IV-1/2 decreases the response of the plasma cholesterol concentration to dietary cholesterol, and in the USA about one in seven of the population is heterozygous (Simopoulos, 2002). In the Dietary Approaches to Stop Hypertension study, those subjects who responded by lowering their blood pressure the most had the genotype AA, whereas those subjects with the genotype GG responded the least (Svetkey et al. 2001).

\section{Implications}

Implications for prevention follow from the earliermentioned current understanding of variability. While clearly genetic variation is a component in the expression of non-communicable diseases, physical activity, diet, the larger environment and, possibly, the intra-uterine environment and later growth are also all important factors. Given the time frame of the current epidemic of obesity and noncommunicable diseases, it is unlikely to represent genetic shifts as the cause. Thus, changes in the environment are the more likely causes, including physical expenditure patterns. Where general guidelines have been issued for the prevention of chronic diseases, the effects of genetic variation on dietary response have not been considered, despite acceptance that such is the case and that it is clear not only that individuals are not predisposed to chronic diseases to the same extent but that response to diet and other interventions will also vary. Accordingly, M Gibney and E Gibney (unpublished results) argue that populationbased dietary guidelines and RDA will not in fact change much because of the relative infrequency of polymorphisms making a major difference to how a nutrient is utilized or, if at a higher frequency, that it would have been, by default, included in earlier recommendations. Thus, public health recommendations are unlikely to be much changed, except to make them more effective, where possible by tailoring them to their audience to be culturally appropriate and to reflect special risks and predisposition, e.g. diabetes in many populations of transitional economies.

The divide between rich and poor countries will affect the use of such approaches. However, the disease burden of non-communicable disease will be greater in the developing world than in the more industrialized world in $<20$ years, which means more global solutions are needed. However, the research efforts against growing obesity prevalence seem at present to be aiming more at a pharmacological answer than the hard task of changing attitudes, behaviours and, increasingly, obesogenic environments.

Implications for disease management were formulated by Mensink \& Plat (2002) when they described the intention of much of the genetic-nutrition interface research as being to 'obtain detailed information on the molecular and metabolic responses of cells and tissues, or even the whole organism, to dietary components (by addressing) the interactions between diet and genetic background, and between diet and different physiological and pathological conditions ...'

It will become easier, perhaps routine, suggests a UK government report, to identify genetic predispositions in family members at risk, and probably those at risk in the population at large (Eaton, 2003), and may lead to the development of novel foods targetted to individuals, families and subgroups within populations (Simopoulos, 2002). While the approach will have to vary with national dietary patterns and the national economy, the end may be individualized prescriptions and genome-based diets. However, in using nutrigenomics to develop foods with helpful phytochemicals to prevent and to treat disease, it has been noted that while nutritional genomics may be a powerful approach for the limited number of plant compounds that are also synthesized in other organisms (e.g. vitamins), applying this approach to other phytochemical pathways meets with obstacles because of the extreme diversity and limited evolutionary distribution of many phytochemicals (Dellapenna, 1999).

Supplementation of the diet with appropriate minerals and vitamins could in some cases help overcome inherited metabolic blocks in key DNA maintenance pathways (Ames, 1998). It would be expected to be especially effective when a mutation (polymorphism) in a gene decreases the binding affinity for its cofactor, resulting in a lower reaction rate, e.g. the common mutation in the methylenetetrahydrofolate reductase gene and other genes in the folate-methionine cycle in relation to developmental defects and cancer (Stover \& Garza, 2002b). Individuals with a polymorphism such as an alanine to valine change in the -9 position of manganese superoxide dismutase appear to benefit more than control subjects from a higher intake of fruit and vegetables and/or vitamin $\mathrm{C}$ in terms of protection against breast cancer (Ambrosone et al. 1999), While this finding would not affect recommendations on eating more fruit and vegetables, it might mean their doctor would encourage such individuals to do so more actively. 
A long-term goal might be to provide personalized dietary advice based on the predicted response to nutrients derived from the genetic profiling of an individual (Trayhurn, 2003). Fenech (2003) goes on to suggest the future need for 'Genome Health Clinics', which among other factors would test whether an individual's genome damage rate is suboptimal or optimal and would guide both diagnosis and treatment. Whether individuals will respond more to personal nutritional advice tailored to their own genetic profile than to advice that is given generally to the population as a whole is currently unknown; although personal advice to quit smoking has greater impact than more general messages.

Based on current information, therefore, it would appear that there is still a long way to go in designing diets for individuals, and even further for populations. If this potential becomes a reality, as does seem likely in some future time, it will not be cheap medicine, identifying individuals at risk, screening them, designing diets etc. If such interventions are not then to be the preserve only of the rich, governments will need to intervene. The response may well be different by country, e.g. in the USA it is likely to remain the preserve of the affluent. In countries with more equitable systems, the test will be how much the system can support. However, if specific genotypes are identified that would clearly benefit from a particular diet, the pressure for screening will be strong. This process, of course, already happens, e.g. in those identified at birth with phenylketonuria, but not, it should be noted, in poorer countries with very much smaller health system resources.

\section{Global implications}

The 2002 World Health Report (World Health Organization, 2002c) found that the top ten risk factors for global disease burden include underweight children and mothers, Fe deficiency, high blood pressure, high cholesterol and obesity; other factors being, for example, vitamin A and $\mathrm{Zn}$ deficiency in the developing world. Clearly, there is an ethical imperative to address these top ten risk factors. Similarly, there is a greater need to address global and national inequities, including such areas as poor water, sanitation and hygiene, and all the other results of poverty, given the increasing consensus (typified most clearly by the adoption of the Millennium Development Goals listed in the United Nations (2000) Millennium Declaration) that a marked improvement in global health is unlikely to happen without such social factors being addressed. As action towards this improvement appears unlikely to happen any time soon, there is an increased pressure to find other interim methods, and this situation explains much of the appeal of the potential of nutrigenomics to many public health nutritionists. However, such approaches need to be considered through a 'poverty lens', as apparently good ideas sometimes have had disastrous effects on those they were meant to help most, e.g. the World Bank's Structural Adjustment policies (Lancet, 1994). In fact, the gaps between rich and poor nations are getting worse (Darnton-Hill \& Coyne, 1998), and the recent UN Human Development Report (United Nations, 2003) has shown many of the gains of the 1970s and 1980s being lost. The richest $1 \%$ of the world's population now receives as much income as the poorest $57 \%$, and overall human development (measured by the $\mathrm{UN}$ as an amalgam of income, life expectancy and literacy) fell in twenty-one countries during the 1990s. A further over-arching issue is how to avoid a gap in the utilization of genomic advances in nutrition and health, as has happened in information technology and the research technology on disease (Singer $\&$ Daar, 2001), where only $10 \%$ of resources are spent on those diseases that account for $90 \%$ of the global burden of disease in the developing countries.

It is appropriate to consider the implications separately, if often overlapping, for poor developing countries and richer industrialized countries, with some continuum according to local and changing situations in transitional economies. While this approach could be criticized as tacit support for elitism in the type of disease prevention and control, in practical terms there seems little alternative if effective interventions are to be put in place. Here, only issues for poorly-resourced health systems will be discussed, although the concern that the benefits of nutrigenomics will go predominantly to those individuals who can buy them, even in affluent countries, has been noted.

\section{Food supply}

Improving household food security and the quality of poor diets will help to improve infant and child survival, physical growth and neuro-intellectual development, improve women's general health and reproductive outcomes, and overall economic development of countries through increased productivity. The role of GM foods in achieving this objective is still unclear to many interested groups. Fresco (2003), for example, feels there is a 'measure of uncertainty as to whether these theoretical advantages (of markedly increased food supply through genomic applications) will translate to greater household food security and improved well-being at the individual level'. There have also been calls for a re-examination of, amongst other issues of concern, the purposes and uses of intellectual property rights policies, in particular those that impact on biotechnologies affecting food production (Borlaug et al. 2004). Improving the quality of diets can be done through public health measures and by improved methods of delivering micronutrients through diets, supplementation and fortification. The genetic makeup of populations may result in rather different outcomes for some subgroups, but at present, most Third World governments have no choice but to feel that the benefit outweighs the demonstrated risks to relatively few members of the population. Where population genetic profiles can be identified and described, as it appears will happen more and more, then levels of fortificants in national fortification programmes can be adjusted or targetted more directly, if economically feasible. Other factors, such as trade, will also influence the impact and role of GM organisms, e.g. in terms of trade to the EU, which is likely to continue prohibiting GM organism imports for some time. 


\section{Prevention of disease}

In terms of the emergence of chronic diseases that results in leaving countries with a double burden of disease, it is unlikely that nutrigenomics will contribute much to help avoid or alleviate these burdens. Affordable public health recommendations are unlikely to change and the need remains for strong measures, probably involving legislation controlling inappropriate advertising to children and selective taxation and duties, along with very active health promotion, possibly emphasizing traditional diets. In this case a recent report from Spain (Hernandez-Diaz et al. 2002) is encouraging. It found, in a Mediterranean population with natural plant foods as the main source of folate, a relationship supporting the hypothesis that dietary folate intake may be an independent protective factor for myocardial infarction. As has been noted, the existing public health measures in countries such as Australia, UK and USA seem to have had little impact on the obesogenic environments that have proved so effective in promoting obesity in these countries (Nestle \& Jacobson, 2000).

\section{Fortification}

There is likely to be an emphasis on fortification as a costeffective potentially-sustainable measure to bring micronutrients to poorer populations. Identification of ethnic profiles of different polymorphisms that will affect some segments of societies, e.g. folic acid and the gene for methylenetetrahydrofolate reductase, is unlikely to be a factor in populations in which the imperative is getting the micronutrient(s) to the vulnerable populations. The possibility of gene shifts in whole populations, such as the suggested increased prevalence of the methylenetetrahydrofolate reductase gene in some populations receiving folic acid and the possible continuation of previously nonviable pregnancies (Stover \& Garza, 2002b), and whether these shifts matter enough to overcome the clear benefits of fortification, will probably depend on the prevalence of the micronutrient deficiencies being addressed. It will also depend on there being economic resources to tackle the problem in some other way. Many countries will not be able to afford alternative approaches that are less costeffective, and hence genetic polymorphism is unlikely to become a factor in their public health decision to fortify. Biofortification, initially with traditional breeding methods but, if consumer acceptance develops, subsequently using GM organisms, is likely to be a real contribution to improving the quality of poor diets in some settings. Nevertheless, micronutrient biofortification, however done, will be only part of the solution (Bouis, 2002b; Lonnerdal, 2003).

\section{Supplementation}

Similarly with supplementation, affluent populations known to have higher levels of, for example, haemochromatosis may find it cost-effective to screen for individuals homozygous for the gene. However, this approach is not an option in countries with poorly-resourced health systems that, in addition to having a higher prevalence of anaemia, are often those with least susceptibility to that polymorphism. In fact, several recent reviews conclude that screening, because of the low penetrance, is not appropriate even in affluent countries (Heath \& FairweatherTait, 2003; Neff, 2003). It is theoretically possible to control Fe deficiency and other anaemias and other micronutrient deficiencies (perhaps especially in populations at high risk of HIV infection and transmission) in developing country settings by supplementation, although the experience to date has not been encouraging. If possible, then the relatively few individuals at greater risk because of specific, relatively rare, polymorphisms may need to be treated when identified at clinics, e.g. by eating modified diets containing less Fe and other relevant micronutrients. Even in areas with a high incidence of malaria, Fe-folate supplementation continues to be of benefit to those populations most at risk, and hence to be recommended as a public health preventive measure, even though it is known not to be the ideal approach in communities with high levels of infectious diseases (Stoltzfus, 2001).

\section{Treatment}

The high costs of the screening and genotype diagnosis of developing novel and functional foods and the poor availability of functional health systems make even the possibility of 'tailored diets' an impossible dream for most populations relying on poorly functioning and poorly resourced health systems. More relevant may be the question asked by Black et al. (2003): 'where and why are 10 million children dying every year?'

\section{Conclusions}

The impact of genetic applications to nutritional problems is here to stay, but will probably end up having unexpected and both welcome and unwelcome outcomes. As suggested by the many bodies now looking at the application of genomic technology and its safety (World Health Organization, 2002d; International Council for Science, 2003), the ethical and public health implications are being examined in a way not seen since the examination of cloning. The conclusions of the present brief review seem to suggest that, overall, the application will be ultimately beneficial in public health terms, but also of a lesser magnitude than sometimes promised. Its greatest potential will be achieved if the technology is harnessed for the greater public, and public health, good with a clear mandate to reduce disparities both within countries and internationally. If this process is to take place, the use of genetic tools for public health purposes must be perceived as a common good that will require active government intervention and international cooperation, and there are some encouraging signs, at least at the policy level, that this objective will be realised. From a public health perspective, the generalizing is a risky enterprise as the field is changing so rapidly and in so many directions, some of which are probably not yet foreseen. Nevertheless, now is the time to sieze opportunities and to put in place safeguards against harm and unexpected consequences, and especially to reduce the 
possibility of a rich-poor world divide in the access to benefits.

In terms of increasing food supplies, preliminary evidence suggests a successful outcome may be less of a boon than initially thought, because many of the possible breeding improvements appear to have already taken place and further improvements will be incremental. More likely is an increase in crop varieties, from genetic insertion of genes and conventional plant breeding, that can be profitably grown in previously-inhospitable environments, such as high-saline conditions and drought-susceptible areas, although growing on marginal lands may well have possible adverse ecological and environmental consequences. Modifying animals to be more efficient converters of plant food also seems to have promise, but is limited. There appears to be more promise in improving the quality of grains and other staples by improving the amount and bioavailability of micronutrients, but even here, population level impact is likely to be modest.

In terms of preventing chronic disease, it would appear that environmental and public health measures will have more impact than genetic manipulation. The main role here may be to identify susceptible populations and add to the strength of advocacy to encourage resources going towards designing effective behaviour change and to mandate changes in national and international food systems. In terms of both treating disease in more susceptible individuals and differing responses to dietary modification, it is likely that there will be some increased targetting of individuals and sub-populations, to make more efficient dietary recommendations. There seems to be an inevitable difference in conclusions, and hence presumably recommendations, for developing countries and affluent countries at this time. First, because the objective in one is for increased diets of sufficient quantity and quality, and in the other enhanced organoleptic properties. The other factor is that benefits and costs of approaches, as with fortification, are greater in developing countries where fewer options exist, although conversely more affluent countries will continue to address diseases affecting fewer and fewer of the population. Affluent countries may also have the resources to address any negative impact of interventions on individuals with a particular polymorphism with individual treatment or dietary advice and, possibly, specific functional foods.

In summary, the debatable answer to the question originally posed, 'will the biotechnology of nutrigenomics make an important difference to the health of the public', is that it will probably not in the immediate future at a population level, especially in resource-poor countries. In this exciting and fast developing interface between nutrition and public health, research will move rapidly ahead and more public health 'tools' will be added to the armamentarium, but these tools are likely to continue to be part of, rather than the whole, solution. Many issues of perceived and actual safety at a population level still need to be addressed and communication of risks and benefits much improved, although this process is starting to happen. It also seems likely that some of the major impacts might come from applications that are currently only aspirations. The most important conclusion is that, unlike the cases of tropical diseases research and development and pharmaceutical accessibility, change should actively aim to reduce inequity, rather than worsen the current situation. Achieving greater equity is after all the greatest contribution of public health, and the interface of public health nutrition and genetics is hopefully set to provide important opportunities for success.

\section{References}

ACC/SCN (2000) Fourth Report on the World Nutrition Situation. Geneva: WHO.

Allison DB, Matz PE, Pietrobelli A, Zannolli R \& Faith MS (2001) Genetic and environmental influences on obesity. In Primary and Secondary Preventive Nutrition, pp. 147-164 [A Bendich and RJ Deckelbaum, editors]. Totowa, NJ: Humana Press.

Ambrosone CB, Freudenheim JL, Thompson PA, Bowman E, Vena JE, Marshall JR, Graham S, Laughlin R, Nemoto T \& Shields PG (1999) Manganese superoxide dismutase (MnSOD) genetic polymorphisms, dietary antioxidants and risk of breast cancer. Cancer Research 59, 602-606.

Ames BN (1998) Micronutrients prevent cancer and delay ageing. Toxicology Letters 102-103, 5-18.

Andersson M, de Benoist B, Darnton-Hill I \& Delange F (2004) Iodine Deficiency in Europe: A Continuing Public Health Problem. Geneva: WHO (In the Press).

Beauchamp TL \& Childress JF (1994) Principles of Biomedical Ethics, 4th ed. New York: Oxford University Press.

Bhargava A, Bouis H \& Scrimshaw N (2001) Dietary intakes and socioeconomic factors are associated with the haemoglobin concentration of Bangladeshi women. Journal of Nutrition 131, 758-764.

Black RE, Morris SS \& Bryce J (2003) Where and why are 10 million children dying every year? Lancet 361, 2226-2234.

Borlaug N, Swaminathan M, Khush G et al. (2004) Securing global food production. In Proceedings of the Congress 'In the Wake of the Double Helix: From the Green Revolution to the Gene Revolution' (In the Press).

Bouis H (2002a) Three criteria for establishing the usefulness of biotechnology for reducing micronutrient malnutrition. Food and Nutrition Bulletin 23, 351-353.

Bouis HE (2002b) Plant breeding: a new tool for fighting micronutrient malnutrition. Journal of Nutrition 132, 491S-494S.

Bouis HE, Lineback D \& Schneeman B (2002) Bio-technologyderived nutritious foods for Developing Countries: needs, opportunities, and barriers. Food and Nutrition Bulletin 23, 342-383.

Brown LR (2001) Eco-Economy: Building an Economy for the Earth, pp. 145-167. Earth Policy Institute. New York: WW Norton \& Co.

Crop Biotech Net (2003a) New applications for agrobiotech. http://www.isaaa.org/kc/CBTNews/2003_Issue/Feb/ CBT_Feb_21.htm\#new

Crop Biotech Net (2003b) Spinach in anthrax vaccine production. http://www.isaaa.org/kc/CBTNews/2003_Issue/March/ CBT_March_14htm\#spi (for more information, contact info@www.greenvaccines.org).

Crop Biotech Net (2003c) ICSU report on new genetics, food and agriculture. http://www.isaaa.org/kc/CBTNews/2003_Issue/ June/CBT_June_12htm\#ics

Darnton-Hill I (1998) Control and prevention of micronutrient malnutrition. Asia Pacific Journal of Clinical Nutrition 7, 2-7. 
Darnton-Hill I, Bloem MW, de Benoist B \& Brown LR (2002) Micronutrient restoration and fortification: communicating change, benefits and risks. Asia Pacific Journal of Clinical Nutrition 11, Suppl. 6, S184-S196.

Darnton-Hill I \& Coyne ET (1998) Feast and famine: socioeconomic disparities in global nutrition and health. Public Health Nutrition 1, 23-31.

Darnton-Hill I, Nishida C \& James PWT (2004) A life course approach to diet, nutrition and the prevention of chronic disease. Public Health Nutrition 7, 107-128.

Davey Smith G \& Ebrahim S (2003) 'Mendelian randomization': can genetic epidemiology contribute to understanding environmental determinants of disease? International Journal of Epidemiology 32, 1-22.

Dellapenna D (1999) Nutritional genomics: manipulating plant micronutrients to improve human health. Science 285, 375-379.

Eaton L (2003) Commission warns against selling genetic tests direct to the public. British Medical Journal 326, 781.

Fenech M (2003) Nutritional treatment of genome instability: a paradigm shift in disease prevention and in the setting of recommended dietary allowances. Nutrition Research Reviews 16, 109-122.

Finucane ML (2002) Mad cows, mad corn and mad communities: the role of socio-cultural factors in the perceived risk of genetically-modified food. Proceedings of the Nutrition Society 61, 31-37.

Food Standards Agency (2003) GM Food: Opening up the Debate. London: Food Standards Agency.

Fresco LO (2003) Which Road to Take? Harnessing Genetic Resources and Making Use of Life Sciences, a New Contract for Sustainable Agriculture. EU Discussion Forum Towards Sustainable Agriculture for Developing Countries. Brussels: European Commission.

Haan EA (2003) The clinical geneticist and the 'new genetics'. Medical Journal of Australia 178, 458-462.

Haddad L (2000) A conceptual framework for assessing agriculture-nutrition linkages. Food and Nutrition Bulletin 21, 367-373.

Heath A-LM \& Fairweather-Tait SJ (2003) Health implications of iron overload: the role of diet and genotype. Nutrition Reviews 61, 45-62.

Heng C-K, Saha N \& Low P-S (1997) Dyslipidaemia in Asia: is there an ethnic difference? Medical Progress December issue, $7-13$.

Hernandez-Diaz S, Martinez-Losa E, Fernandez-Jarne E, SerranoMartinez M \& Martinez-Gonzalez MA (2002) Dietary folate and the risk of nonfatal myocardial infarction. Epidemiology 13, 700-706.

International Council for Science (2003) New genetics, food and agriculture: scientific discoveries - societal dilemmas. Executive summary. http://iscudqba.alias.domicile.fr/Library/ reviews/GMOs/GMO_Exec Summary.pdf

Jackson AA ( 2003) Genetically modified organisms. Discussion Notes Prepared for British Medical Association Round Table Meeting June 1-3.

Karter AJ (2002) Commentary: race, genes, and health - in search of a middle ground. International Journal of Epidemiology 32, 26-28.

Kavalier F \& Kent A (2003) Genetics and the general practitioner. White paper takes the first steps down a long road (editorial). British Medical Journal 327, 2-3.

Keys A, Anderson JT \& Grande F (1965) Serum cholesterol response to changes in the diet. III. Differences among individuals. Metabolism 14, 766-775.

Khush GS (2001) Challenges for meeting the global food and nutrient needs in the new millennium. Proceedings of the Nutrition Society 60, 15-26.
Khush GS (2002) The promise of biotechnology in addressing current nutritional problems in developing countries. Food and Nutrition Bulletin 23, 354-357.

Krauss RM (2000) Genetic recipes for heart-healthy diets. American Journal of Clinical Nutrition 71, 668-669.

Lancet (1994) Structural adjustment too painful? (editorial). Lancet 344, 1377-1378.

Larsen J (2003) Population growth leading to land hunger. http:www.earth-policy.org/Updates/Update21.htm (accessed 23 January, 2003).

Lonnerdal B (2003) Genetically modified plants for improved trace element nutrition. Journal of Nutrition 133, 1490S-1493S.

Martinez JA (2000) Body-weight regulation: causes of obesity. Proceedings of the Nutrition Society 59, 337-345.

Masson LF, McNeill G \& Avenell A (2003) Genetic variation and the lipid response to dietary intervention: a systematic review. American Journal of Clinical Nutrition 77, 1098-1111.

Maziya-Dixon B, Kling JG, Menkir A \& Dixon A (2000) Genetic variation in total carotene, iron, and zinc contents of maize and cassava genotypes. Food and Nutrition Bulletin 21, 419-422.

Mensink RP \& Plat J (2002) Post-genomic opportunities for understanding nutrition: the nutritionist's perspective. Proceedings of the Nutrition Society 61, 401-404.

Murdur G (2003) Controversy grows over India's geneticallymodified potato. British Medical Journal 326, 1351.

Neff LM (2003) Current directions in hemochromatosis research: towards an understanding of the role of iron overload and the HFE gene mutations in the development of clinical disease. Nutrition Reviews 61, 38-42.

Nestle M \& Jacobson MF (2000) Halting the obesity epidemic: a public health policy approach. Public Health Reports 115, $12-24$.

Ordovas JM (2004) The quest for cardiovascular health in the genomic era: nutrigenics and plasma phospholipids. Proceedings of the Nutrition Society 63, 145-152.

Paddock W \& Paddock P (1967) Times of Famines. Boston, MA: Little Brown and Company.

Pinstrup-Andersen P (2000) Improving human nutrition through agricultural research: overview and objectives. Food and Nutrition Bulletin 21, 352-355.

Popkin BM (2002) An overview on the nutrition transition and its health implications: the Bellagio Meeting. Public Health Nutrition 5, 93-103.

Rowland IR (2002) Genetically modified foods, science, consumers and the media. Proceedings of the Nutrition Society $\mathbf{6 1}$ $25-29$.

Saha N, Heng CK, Mozoomdar BP, Reuben EM, Soh HT, Low PS, Tay JSH, Liu Y \& Hong S (1995) Racial variation of factor VII activity and their correlates in healthy Chinese and Indians at low and high risk for coronary artery disease. Atherosclerosis 117, 33-42.

Simopoulos AP (2002) Genetic variation and dietary response: nutrigenetics/nutrigenomics. Asia Pacific Journal of Clinical Nutrition 11, Suppl. 6, S117-S128.

Singer PA \& Daar AS (2001) Harnessing genomics and biotechnology to improve global health equity. Science 294, 87-89.

Stevens J \& Nowicki EM (2003) Body mass index and mortality in Asian populations: implications for obesity cut-points. Nutrition Reviews 61, 104-113.

Stoltzfus RJ (2001) Summary: implications for research and programs. Journal of Nutrition 131, Suppl. 2, 697S-701S.

Stover PJ \& Garza C (2002a) Bringing individuality to public health recommendations. Journal of Nutrition 132, 2476S-2480S. 
Stover PJ \& Garza C (2002b) Molecular and genetic considerations for long-term nutrition interventions. Asia Pacific Journal of Clinical Nutrition 11, Suppl. 6, S129-S136.

Svetkey LP, Moore TJ, Simons-Mortorf DG, Appel LJ, Bray GA, Sacks FM, Ard JD, Moretensen RM, Mitchell SR, Contin PR \& Kesari $\mathrm{M}$ for the DASH Collaborative Research Group (2001) Angiotensinogen genotype and blood pressure response in the Dietary Approaches to Stop Hypertension (DASH) study. Journal of Hypertension 19, 1949-1956.

Talmud PJ (2004) How to identify gene-environment interactions in a multifactorial disease: $\mathrm{CHD}$ as an example. Proceedings of the Nutrition Society 63, 5-10.

Tiret L (2002) Gene-environment interaction: a central concept in multifactorial diseases. Proceedings of the Nutrition Society 61, 457-463.

Toumani Touré A \& Compaoré B (2003) Africa needs a level playing field for trade. International Herald Tribune 12 July issue, 4.

Trayhurn P (2003) Nutritional genomics - 'Nutrigenomics'. British Journal of Nutrition 89, 1-2.

United Nations (2000) UN Millennium Declaration September 2000. http://www.un.org/millennium/declaration/ ares552e.htm

United Nations (2003) Human Development Report 2003. United Nations Development Programme. New York: Oxford University Press.

Vincent S, Planells R, Defoort C, Bernard M-C, Gerber M, Prudhomme J, Vague P \& Lairon D (2002) Genetic polymorphisms and lipoprotein responses to diets. Proceedings of the Nutrition Society 61, 427-434.

Wahlqvist ML (2002) Focusing on novel foods: their role, potential and safety. Asia Pacific Journal of Clinical Nutrition 11, Suppl. 6, S598-S599.

Walter P, Hornig D \& Moser U (editors) (2001) A conceptual approach for scientifically based guidelines. In Functions of
Vitamins Beyond Recommended Dietary Allowances, pp. 1-3. Basel: Karger.

Welch RM \& Graham RD (2000) A new paradigm for world agriculture: productive, sustainable, nutritious, healthful food systems. Food and Nutrition Bulletin 21, 361-366.

Wells JM \& Bennik MHJ (2003) Genomics of food-borne bacterial pathogens. Nutrition Research Reviews 16, 21-35.

Whincup PH, Gilg JA, Papacosta O, Seymour C, Miller GJ, Alberti KGMM \& Cook DG (2002) Early evidence of ethnic differences in cardiovascular risk: cross sectional comparison of British South Asian and white children. British Medical Journal 324, 1-6.

World Health Organization (2002a) Obesity: Preventing and Managing the Global Epidemic. WHO Technical Report Series no. 894. Geneva: WHO.

World Health Organization (2002b) Programming of Chronic Disease by Impaired Fetal Nutrition: Evidence and Implications for Research and Intervention Strategies. WHO/NHD/ 02.3, WHO/NPH/02.1. Geneva: WHO.

World Health Organization (2002c) The World Health Report 2002. Reducing Risks, Promoting Healthy Life. Geneva: WHO.

World Health Organization (2002d) Genomics and World Health. Summary. Geneva: WHO.

World Health Organization (2003) Diet, Nutrition and the Prevention of Chronic Disease. Report of a WHO/FAO Technical Consultation. Geneva: WHO.

World Health Organization (2004) Report of a WHO Expert Consultation on Appropriate BMI for Asian Populations and Its Implications for Policy and Intervention Strategies. Geneva: WHO (In the Press).

Yajnik CS (2002) The lifecycle effects of nutrition and body size on adult obesity, diabetes and cardiovascular disease. Obesity Reviews 3, 217-224.

Zhang Y, Proenca R, Maffei M, Barone M, Leopald L \& Friedman JM (1994) Positional cloning of the mouse obese gene and its human homologue. Nature 372, 425-432. 